\title{
Escrita do gênero relatório de estágio supervisionado na formação inicial do professor brasileiro
}

\section{The Writing of the Genre Supervised Internship Report in Brazilian Teacher Education}

Wagner Rodrigues Silva*

Universidade Federal do Tocantins

Conselho Nacional de Desenvolvimento Científico e Tecnológico

Araguaína - Tocantins / Brasil

RESUMO: Neste artigo, a escrita de professores em formação nas licenciaturas em Geografia, História e Matemática é apresentada como objeto de investigação na Linguística Aplicada (LA). A descrição do gênero relatório de estágio supervisionado, produzido pelos professores em formação inicial mencionados, é o principal objetivo desta pesquisa. A metodologia de investigação científica é informada pela abordagem transdisciplinar da LA. Alguns estudos da Linguística SistêmicoFuncional (LSF) e do Letramento do Professor são os principais referenciais utilizados. Os resultados da pesquisa revelam uma não sistematização do trabalho pedagógico com a escrita dos relatórios nas licenciaturas focalizadas, o que pode resultar em restriçōes para o fortalecimento do letramento crítico, idealizado para o futuro professor no local de trabalho. Alguns encaminhamentos teóricometodológicos são realizados, mais diretamente, para os estudos sobre gêneros desenvolvidos na LSF.

PALAVRAS-CHAVE: Linguística Sistêmico-Funcional; letramento do professor; Linguística Aplicada.

ABSTRACT: In this paper, the writing produced by pre-service teachers in Geography, History and Mathematics undergraduation courses is presented as object of research in the Applied Linguistics (AL). The description of the genre supervised internship report, produced by the pre-service teachers mentioned, is the main aim of this research. The methodology of scientific research is informed by the transdisciplinary approach of AL. Some studies developed in the fields of Systemic Functional Linguistics (SFL) and Teacher Literacy are the main references used in this investigation. The research results show a non-systematized pedagogical work with the writing of reports in the courses studied, what may result in

* wagnerodriguesilva@yahoo.com 
restrictions to the empowerment of the critical literacy idealized for the future teacher in his/her workplace. Some theoretical and methodological contributions are pointed out, more directly, for the studies of genres developed in the SFL.

KEYWORDS: Systemic Functional Linguistics; teacher literacy; Applied Linguistics.

Teoria de gênero traz o conhecimento cultural inconsciente para a consciência, descrevendo como usamos a linguagem para fazer qualquer coisa, refletindo criticamente sobre o que nossa vida cultural envolve. ${ }^{1}$

Suzanne Eggins

\section{Introdução}

São inúmeros os trabalhos acadêmicos sobre gêneros textuais, resultados de pesquisas científicas e disponíveis para consulta em diferentes publicações nacionais ou internacionais. Contribuir com a produção científica sobre o assunto torna-se um desafio a mais para o pesquisador. Além de evitar a reprodução pouco produtiva do conhecimento científico sobre os gêneros textuais, temos outro desafio neste artigo: articular a abordagem dos gêneros textuais, proposta no âmbito da Linguística Sistêmico-Funcional (LSF), e a abordagem investigativa da transdisciplinaridade, proposta no âmbito da Linguística Aplicada (LA). Tal articulação será realizada por meio da descrição do gênero relatório de estágio supervisionado, produzido por professores em formação inicial nas licenciaturas, os quais são aqui denominados de alunos-mestre. ${ }^{2}$

\footnotetext{
1 "Genre theory is about bringing this unconscious cultural knowledge to consciousness by describing how we use language to do thing, and reflecting critically on just what our cultural life involves" (EGGINS, 2004, p. 84). Neste artigo, todas as traduções são de nossa responsabilidade.

${ }^{2}$ Este artigo contribui para os projetos de pesquisa "Formação Inicial de professores mediada pela escrita" (CNPq/CAPES 400458/2010-1) e "Implicações dos relatórios de estágio supervisionado para a formação inicial de professores" (CNPq 501123/ 2009-1), desenvolvidos no âmbito do grupo de pesquisa Práticas de Linguagens em Estágios Supervisionados - PLES (UFT/CNPq). Foi apresentado no simpósio "Práticas de linguagens em estágios supervisionados", no $2^{\circ}$ Colóquio Internacional de Estudos Linguísticos e Literário, realizado na Universidade Estadual de Maringá - UEM, em junho de 2012, e no VIII Congresso da ALSFAL - Associação de Linguística Sistêmico-Funcional da América Latina, Montevidéu, Uruguai, em setembro de 2012 (CNPq 454362/2012-9).
} 
Conforme afirmado na epígrafe supramencionada, as teorias dos gêneros textuais revelam como a linguagem é cotidianamente utilizada, refletindo a cultura em que os usuários da língua estão inseridos. Retomar os relatórios escritos de estágio supervisionado como objeto de investigação científica, no campo transdisciplinar da LA, traduz-se no enfoque do contexto de formação inicial de professores, nas licenciaturas. Pela análise desses documentos escritos, é possível depreender algumas informações sobre o funcionamento das disciplinas de estágio supervisionado obrigatório e, até mesmo, das demais disciplinas integrantes da matriz curricular da licenciatura. Esta investigação sobre/com a linguagem em contexto de formação inicial de professores, em diferentes licenciaturas, justifica a inserção deste trabalho na área de formação de professores, na LA.

$\mathrm{O}$ trabalho com a linguagem na formação inicial de professores, em diferentes licenciaturas, não se restringindo aos cursos que a tem como principal conteúdo de estudo, também se constitui objeto de investigação da LA. Lamentavelmente, tais licenciaturas parecem esquecidas pelos linguistas aplicados, conforme podemos evidenciar em Maria Antonieta A. Celani (2008, p. 25), que, ao focalizar o processo reflexivo pela linguagem, na formação inicial de professores de língua, não menciona as demais licenciaturas, as quais também são responsáveis pela formação de professores. Os egressos desses cursos, por exemplo, terão a leitura e a escrita como práticas de linguagem no futuro lugar de trabalho - escolas de educação básica.

Assumimos a abordagem qualitativa de investigação científica, instaurada pelo enfoque discursivo-textual sobre diferentes relatórios escritos confrontados nas análises realizadas. Para tanto, compartilhamos do posicionamento assumido por Alaistair Pennycook (2003, p. 26), ao afirmar que "uma abordagem aos textos fundamentada na LAC [(Linguística Aplicada Crítica)] necessita de alguma forma de ação pedagógica, que investigue caminhos pelos quais os aprendizes possam ser encorajados a resistir e mudar os discursos que constroem suas vidas". Com esta pesquisa, também pretendemos contribuir para o fortalecimento do letramento do professor em formação inicial, especialmente nos estágios supervisionados obrigatórios das licenciaturas brasileiras.

Os estudos do letramento auxiliam na construção da abordagem crítica da LA assumida nesta pesquisa. Letramento são práticas sociais de uso da escrita com propósitos diversos, nas infindáveis interações do cotidiano. Tais práticas podem envolver relaçōes assimétricas, disputadas de poder ou conflitos sociais, conforme distribuição de valores simbólicos atribuídos às situaçōes em que a escrita está inserida. Tal distribuição está condicionada aos atores integrantes das interações 
sociais (BARTON; PAPEN, 2010; KLEIMAN, 2006; 2001). Nosso enfoque nesta pesquisa recai sobre as práticas de letramento acadêmico em que a produção dos relatórios de estágio supervisionado está envolvida. Essa produção é informada por outras práticas de escrita características de esferas sociais diversas.

A perspectiva transdisciplinar da LA corrobora a abordagem qualitativa de pesquisa. Compreendemos por transdisciplinaridade "não apenas a utilização e o empréstimo de perspectivas teórico-metodológicas de outras disciplinas, mas também, e mais importante, a transformação destas últimas no processo" de construção de objetos complexos de investigação científica (KLEIMAN, 2001, p. 18). Esses objetos são visualizados pelo compartilhamento de saberes de diferentes disciplinas, responsáveis pelo tratamento dos dados por instrumentos e perspectivas diversas de análise, evitando a simplificação dos resultados produzidos. Tal perspectiva envolve ainda investigaçóes comprometidas politicamente com o fortalecimento dos colaboradores, dos participantes ou do próprio contexto focalizado no trabalho científico (KLEIMAN, 1998; PENNYCOOK, 2003; 1998; SIGNORINI, 1998).

Considerando nosso interesse pelas produçōes escritas produzidas em outras licenciaturas, excetuando o curso de Letras, que historicamente tem a linguagem como principal objeto de estudo, foram analisados aproximadamente seiscentos relatórios de estágio supervisionado das licenciaturas em Geografia, História e Matemática, produzidos durante seis anos consecutivos, no campus universitário de Araguaína, pertencente à Universidade Federal do Tocantins (UFT). Esses documentos estão disponibilizados para pesquisa nos seguintes centros de documentação, cujos acervos são alimentados continuamente: Centro Interdisciplinar de Memória dos Estágios Supervisionados das Licenciaturas (CIMES) e Centro de Documentação Histórica $(\mathrm{CDH})$. No primeiro, estão arquivados os relatórios de estágio das seguintes licenciaturas ofertadas no campus mencionado: Biologia, Letras (Língua Portuguesa e Língua Inglesa), Física, Geografia, Química e Matemática. Apenas as produções escritas da licenciatura em História estão arquivadas no segundo centro mencionado. ${ }^{3}$

\footnotetext{
${ }^{3}$ Como não tínhamos interesse em trabalhar aqui com a licenciatura em Letras, cujo enfoque das pesquisas na LA já é consensual, escolhemos apenas as licenciaturas em Geografia, História e Matemática. As demais licenciaturas são cursos novos na instituição, implementados em 2009, com subsídios do Programa de Apoio a Planos de Reestruturação e Expansão das Universidades Federais (Reuni).
} 
Este artigo está organizado em três partes principais: Prática de escrita na formação do professor, Contexto na constituição do relatório de estágio e Discursos sobre o estágio supervisionado. Na primeira, caracterizamos algumas funções desempenhadas pelas denominadas escrita reflexiva e impressionista na formação inicial de professor na licenciatura, as quais são confrontadas com a escrita acadêmica, característica da tradição da esfera universitária. Na segunda, sintetizamos a abordagem dos gêneros textuais, proposta no âmbito da linguística sistêmico-funcional (LSF), e descrevemos a estrutura esquemática dos relatórios de estágio supervisionado. Na terceira, analisamos alguns discursos característicos dos principais elementos caracterizadores da estrutura esquemática do gênero focalizado - introdução, desenvolvimento e consideraçōes finais.

\section{Prática de escrita na formação do professor}

O relatório escrito, apresentado como trabalho final das disciplinas de estágio supervisionado, nas licenciaturas, é objeto de investigação nas pesquisas científicas que realizamos e coordenamos há aproximadamente três anos. Nosso interesse por esses escritos se justifica pelas iniciativas de produção textual que tomam corpo, nas últimas décadas, no cotidiano acadêmico. Conforme Raquel S. Fiad e Lilian L. M. da Silva (2009, p. 123), tais iniciativas procuram estimular uma produção escrita "de caráter mais narrativo e subjetivo, na qual a maior referência é o próprio autor, sua percepção dos fatos, suas experiências e formas de significar”.

Quais seriam as justificativas para o crescente interesse pelo uso dessa escrita marcadamente subjetiva no espaço acadêmico, mais precisamente em cursos de formação de professores? Mantendo o gênero relatório de estágio no centro da discussão, acreditamos que a escrita reflexiva, no termo utilizado por Burton (2009), dentre outros ganhos para a formação inicial do professor, possa reduzir a probabilidade do aluno-mestre se esconder entre as inúmeras vozes legitimadas na esfera acadêmica, reproduzindo alguns discursos despercebidos ou que não sejam, necessariamente, por ele aceitos ou, até mesmo, produzidos.

Diferentemente da escrita esperada nos tradicionais gêneros acadêmicos, como ensaio, monografia, relatório técnico, resenha e resumo, a escrita reflexiva se configura como uma atividade bastante versátil:

não só apoia a reflexão e a aprendizagem profissional em muitos contextos de ensino, mas pode ser uma atividade prazerosa e socializável. Há professores que, antes de escreverem sobre a própria 
prática profissional, não têm um posicionamento assumido diante da prática, mas percebem que escrever sobre sua prática profissional traz novos insights e entendimentos, além do senso de realização pessoal e profissional. A escrita reflexiva permite a troca de experiências e saberes com outros profissionais (BURTON, 2009, p. 1, grifo nosso). ${ }^{4}$

Nos dois últimos parágrafos, tentamos sintetizar algumas das justificativas do uso da escrita reflexiva no contexto de formação inicial de professores, porém, os prováveis ganhos podem não se materializar, caso essa atividade de escrita não seja acompanhada por alguma orientação mais elaborada ou sistematizada. Nos relatórios de estágio, a subutilização da escrita reflexiva se daria quando o aluno-mestre, minimamente, não associa a experiência vivenciada, nas escolas de educação básica, ao conhecimento teórico trabalhado na própria licenciatura, configurando o referido gênero num texto predominantemente narrativo e descritivo, informado, quando muito, por impressões diversas.

O receio do que podemos denominar aqui de escrita impressionista revela a tensão no uso do gênero relatório como trabalho final, escrito para as disciplinas de estágio supervisionado. Assim como evidenciam os resultados das nossas pesquisas, a investigação realizada por Fiad e Silva (2009, p. 127), com o denominado relato de estágio, mostra que, mesmo quando o alunomestre parece "se colocar como desejoso de acolher características mais subjetivas ou singulares daquele que escreve, precisa operar com a força de uma herança, tradição ou valor, que modela seu pensamento e sua linguagem”.

Essa tradição também modela o pensamento e a linguagem dos formadores responsáveis pelas disciplinas de estágio supervisionado nas licenciaturas, como, por exemplo, quando se deseja que, na escrita do relatório, o aluno-mestre articule a literatura acadêmica, trabalhada nas aulas da licenciatura, com a experiência vivenciada nas atividades práticas dos estágios (MELO, 2011). Inevitavelmente, tal tradição pode ser tomada como parâmetro de avaliação do relatório. Apesar da característica bastante subjetiva da escrita reflexiva desejada para o relatório, este também compartilha de características comuns aos tradicionais gêneros acadêmicos.

\footnotetext{
4 "Reflective writing is a versatile resource. Writing not only supports reflection and professional learning in many teaching settings, it can also be a pleasurable and sociable activity. Many teachers are not sure what they think before they write, but find that writing about their practice brings new insights and understanding, a sense of personal and professional accomplishment, and a readiness to share insights with others".
} 
É sobre essa tensão no uso do relatório nas disciplinas de estágio supervisionado que nos deteremos mais diretamente neste artigo. Concebendo a escrita como atividade, David Barton e Uta Papen (2010) destacam que pesquisas sobre o fenômeno da escrita são essenciais para compreender a vida e as instituições contemporâneas. Ainda segundo os autores, "para compreender como a escrita ou os textos escritos são utilizados por diferentes pessoas, em diferentes contextos, nós precisamos investigar os valores, crenças e comportamentos, que estão associados com diferentes formas de escrita" (BARTON; PAPEN, 2010, p. 9).5

A instabilidade no gênero focalizado, conforme mostraremos adiante, é característica do trabalho de profissionalização do professor em formação inicial, desenvolvido nas licenciaturas e, mais especificamente, nos estágios supervisionados obrigatórios. Conforme já mostraram alguns estudos sobre a disciplina, desenvolvidos na Ciência da Educação e na LA, apesar de possibilitar a inserção proveitosa do aluno-mestre nas escolas de educação básica, "muitas vezes, o estágio se constitui em uma mera obrigação burocrática, desconsiderando seu potencial na formação" (GISI; MARTINS; ROMANOWSKI, 2009, p. 208). Num curto espaço de tempo, em menos de um semestre, o aluno-mestre e o formador podem se encontrar confusos em meio a inúmeros documentos orientadores das atividades do estágio, às quais se somam outras tantas demandas da própria esfera acadêmica.

A burocratização do estágio, informada, dentre outras atividades, pelo cumprimento de carga horária específica e comprovação de trabalhos realizados, respinga na escrita dos relatórios, situando-o na fronteira com o gênero portfólio, conforme discutido em outro momento (SILVA, 2012a). Nessa perspectiva, o trabalho escrito final da disciplina resultaria na compilação de fichas de acompanhamento, atividades didáticas, fotografias, dentre outros documentos comprobatórios da experiência vivenciada. ${ }^{6}$ Normalmente, o

\footnotetext{
5 "In order to understand how writing and written texts are used by different people in different contexts, we need to examine the values, beliefs and behaviors that are associated with different forms of writing".

${ }^{6}$ Conforme Maria Irene Miranda (2008, p. 15), “o estágio, nos cursos de formação é, quase sempre, reduzido a uma atividade de prática instrumental que limita o papel do aluno-estagiário a mero observador e conseqüentemente, empobrece as possibilidades de ação na escola-campo. Nessa vertente, o estagiário tende a descrever o contexto escolar, preenchendo fichas e formulários pré-estabelecidos ou padronizados, em detrimento de uma análise mais crítica dos fatores determinantes da realidade educacional".
} 
mesmo rótulo, "relatório de estágio", identifica esse trabalho escrito final, com configurações muito diversas.

Reconhecemos os ganhos advindos do uso de portfólios em contextos de formação, conforme amplamente discutido por Benigna M. de F. Villas Boas (2010), na Ciência da Educação. Esse gênero evidencia uma prática social característica da cultura escrita da escola. Desde as séries iniciais, professoras produzem portfólios bimestrais ou semestrais com as primeiras atividades escolares trabalhadas pelas crianças. A subutilização dessa ferramenta, bastante comum no estágio supervisionado obrigatório das licenciaturas, acontece quando a construção do portfólio não se configura como um trabalho consciente do produtor, com evidências do progresso na formação, incluindo reflexões críticas sobre o desenvolvimento do próprio trabalho realizado (VILLAS BOAS, 2010, p. 33).

Finalmente, interessa-nos aqui, enquanto linguistas aplicados, além de contribuir com as pesquisas científicas sobre gêneros textuais, apresentar alguns encaminhamentos para o trabalho com relatórios de estágio, em contextos de formação inicial de professores. A noção de gênero catalisador, proposta por Signorini (2006), oferece algum norte para os usos idealizados do gênero tematizado na formação inicial de professores. Os relatórios, portanto, precisam realmente funcionar como gêneros catalisadores, "que favorecem o desencadeamento e a potencialização de ações e atitudes consideradas mais produtivas para o processo de formação, tanto do professor quanto de seus aprendizes" (SIGNORINI, 2006, p. 8). ${ }^{7}$

\section{Contexto na constituição do relatório de estágio}

A tensão evidente na significativa instabilidade do gênero relatório de estágio é motivada por práticas sociais instauradas na licenciatura e, em especial, na disciplina de estágio. Essas práticas são aqui concebidas como formas

\footnotetext{
${ }^{7}$ A autora continua afirmando que os gêneros catalisadores funcionam como "locus no sentido de um espaço regulado de natureza linguístico-discursiva e também sociocognitiva, feito de trilhos e andaimes indispensáveis à construção do novo: novos gêneros feitos da mistura ou entrelaçamento de outros já conhecidos; novos textos visando novos interlocutores e novas indagações, mas ancoradas na experiência com gêneros e práticas bem conhecidas, inclusive escolares; novos objetos de ensino orientados por novas concepçôes e novos objetivos, mas articulados em sequências de atividades que se integram a práticas de ensino já existentes" (SIGNORINI, 2006, p. 8-9).
} 
socialmente reguladas de ação no cotidiano. Numa abordagem crítica do discurso, podemos afirmar que, ao escrever o relatório, o aluno-mestre recontextualiza práticas sociais experienciadas nas atividades teóricas e práticas dos estágios supervisionados obrigatórios. Por trazer semiotizadas na materialidade textual essas práticas sociais, o texto é tomado nesta investigação como unidade de análise linguística (VAN LEEUWEN, 2008).

Nosso interesse pela LSF se justifica pelo trabalho com o texto enquanto unidade de análise. Considerado como produto da interação social, o texto é resultado das escolhas linguísticas realizadas pelos usuários no sistema linguístico de referência. Essas escolhas acontecem nos níveis micro e macrotextual, compreendendo escolhas lexicogramaticais e estruturais na composição esquemática do gênero, respectivamente. Tais escolhas são motivadas pelos contextos de situação e de cultura em que ocorre a interação social pela linguagem, daí o texto ser descrito como "língua em contexto" por Michael A. K. Halliday (1973, p. 68). Suzanne Eggins e James Martin (1997, p. 232) destacam que "cada texto parece trazer com ele algumas influências do contexto em que foi produzido. Poderíamos dizer que o contexto entra 'dentro' do texto, influenciando as palavras e estruturas que os produtores do texto utilizam". 8

Nos termos de Eggins (2004, p. 20), a LSF é "uma abordagem semântico-funcional da linguagem, explora tanto como as pessoas usam a linguagem em diferentes contextos e como a linguagem é estruturada para utilização como um sistema semiótico". ${ }^{9}$ Essa abordagem justifica a investigação do gênero relatório de estágio em função da compreensão do contexto de formação do aluno-mestre na licenciatura brasileira.

Na FIG. 1, sintetizamos a dinâmica de funcionamento da linguagem conforme a LSF. Os três planos representados por círculos funcionam "simultaneamente e interconectadamente", ou seja "escolhas em um plano determinam as escolhas no plano seguinte" (VIAN JR., 2011, p. 83).

\footnotetext{
8 "Each text appears to carry with it some influences from the context in which it was produced. Context, we could say, gets 'into' text by influencing the words and structures that text-producers use".

9 "a functional-semantic approach to language which explores both how people use language in different contexts, and how language is structured for use as a semiotic system".
} 


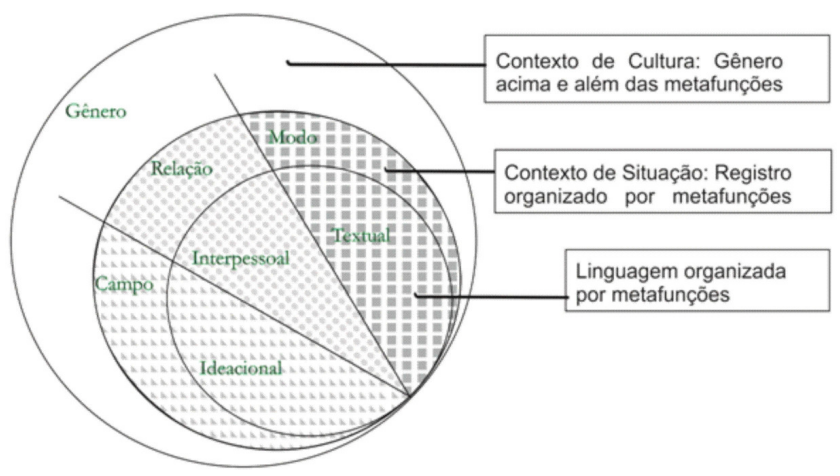

FIGURA 1 - Do contexto de cultura às metafunções da linguagem Fonte: BARBARA; MACÊDO, 2009, p. 94.

A LSF identifica três maneiras simultâneas dos enunciados produzirem sentidos: (1) recursos ideacionais, que dizem respeito à interpretação da experiência; (2) recursos interpessoais, que dizem respeito à negociação das relaçóes sociais; (3) recursos textuais, que dizem respeito ao fluxo de informaçóes (MARTIN; WHITE, 2005, p. 7). ${ }^{10}$ Os três sentidos mencionados correspondem às metafunções da linguagem - ideacional, interpessoal e textual-, as quais são realizadas por padróes lexicogramaticais do sistema linguístico. Na FIG. 1, as metafunções correspondem ao plano mais interno. Tais sentidos são focalizados nas seguintes perguntas propostas por Orlando Vian Jr. (2011, p. 69) para auxiliar na interpretação dos contextos de situação e de cultura: "(1) o que está acontecendo?; (2) quem participa desse evento?; e (3) qual o papel da linguagem?”. Essas perguntas nortearão a análise do gênero relatório de estágio supervisionado, ao focalizarmos aqui os níveis macro e microtextual.

As metafunções são desdobradas, respectivamente, em três categorias configuradoras das variáveis de registro-campo, relação e modo-, correspondem ao plano intermediário da FIG. 1, definindo o contexto de situação, onde se instaura a interação mais imediata. Ainda na FIG. 1, finalmente, no plano mais externo, está o contexto cultural, mais abstrato quando comparado ao anterior, onde são construídas as inúmeras práticas sociais que dão forma aos gêneros textuais. Nas interlocuções cotidianas, em outras palavras, formas de interação social passam

10 "Ideational resources are concerned with construing experience. Interpersonal resources are concerned with negotiating social relations. Textual resources are concerned with information flow". 
culturalmente por alguma estabilização ou padronização, podendo algumas dessas serem institucionalizadas, dada a função que passam a exercer nas diferentes instituições da sociedade letrada em que estamos inseridos. Tais formas construídas socialmente se configuram em gêneros. Na perspectiva transdisciplinar da Linguística Aplicada, o diálogo que estabelecemos aqui com pesquisas realizadas em outras disciplinas do conhecimento nos auxilia a compreender o contexto cultural em que os relatórios circulam, logo, contribui para a caracterização do gênero textual.

Caracterizamos o contexto de situação dos relatórios de estágio supervisionado a partir da reprodução do quadro expositivo, produzido por Wagner R. Silva e Emilia Fajardo-Turbin (2011, p. 107). No QUADRO 1, são apresentadas definiçōes das categoria de registro, as quais são seguidas pela caracterização das variáveis do próprio relatório, que por sua vez podem sofrer alterações pontuais, dependendo da situação em que o relatório é produzido e circula. Além da própria instituição de ensino superior, a licenciatura e o formador responsável pela disciplina são variáveis que interferem diretamente na configuração do registro, mais especificamente, ou mesmo do gênero textual, de forma mais ampla.

\section{QUADRO 1}

Contexto de situação: variáveis de registro

\begin{tabular}{l|l}
\hline Variáveis de Registro & \multicolumn{1}{c}{$(+)$ Definião e (\#) Análise } \\
\hline $\begin{array}{l}\text { Discurso de Campo } \\
\text { (field of discourse) }\end{array}$ & $\begin{array}{l}\text { (+) Codificação da experiência. Aquilo que é dito. } \\
\text { em discurso acadêminas de estágio supervisionado, envolvendo os espaços } \\
\text { universitário e escolar. } \\
\text { (+) Significados interpessoais. As relaçōes estabelecidas entre os } \\
\text { interactantes. }\end{array}$ \\
\hline $\begin{array}{l}\text { Discurso de Relação } \\
\text { (tenor of discourse) }\end{array}$ & $\begin{array}{l}\text { (\#) Produtores: alunos-mestre matriculados em disciplinas de } \\
\text { estágio, cumprindo uma atividade acadêmica. Leitores imediatos: } \\
\text { docentes responsáveis pelas disciplinas de estágio, os quais avaliam } \\
\text { imediatamente o mérito do trabalho. Leitores potenciais: outros } \\
\text { alunos-mestre dos estágios ou quaisquer interessados nos } \\
\text { documentos, os quais têm acesso aos documentos nos centros de } \\
\text { documentação. }\end{array}$ \\
\hline
\end{tabular}

11 "Field: what the language is being used to talk about; Tenor: the role relationships between the interaction; Mode: the role language is playing in the interaction" (EGGINS, 2004, p. 90). 
Discurso de modo

(mode of discourse)
(+) Significados textuais. O papel exercido pela língua na interação.

(\#) Documento impresso com predominância da língua escrita, produzido a partir da observação que se deseja crítica da experiência vivenciada em disciplinas de estágio. Podem ser apropriados ou utilizados textos pertencentes a diferentes gêneros, realizados a partir de diversas linguagens.

Fonte: Elaboração a partir de Eggins (2004, p. 90).

Conforme Eggins e Martin (1997, p. 236), "a teoria do gênero esclarece que textos, exercendo atividades diferentes na cultura, irão desdobrar-se em formas diferentes, funcionando por meio de diferentes estágios ou etapas”. Realizar descrição de gêneros, portanto, não significa regulamentar modelos padronizados, afinal, ainda conforme os autores mencionados, a "relação entre contexto e texto é teorizada como probabilística e não determinista”. ${ }^{12}$ Mas qual a concepção de gênero textual assumida nesta investigação? De acordo com Martin (1997, p. 13), concebemos gênero como representação de "sistema de estágios informados por processos sociais, por meio dos quais os sujeitos sociais, inseridos numa dada cultura, vivem suas vidas". ${ }^{13}$

O estudo dos gêneros também compreende reflexão crítica sobre aspectos ideológicos semiotizados por meio da estrutura esquemática instanciada, a qual estará a serviço de alguém ou alguma instituição. Tal estudo não se limita à descrição da estrutura textual. Nessa perspectiva, precisamos nos questionar a respeito da instabilidade constitutiva da estrutura esquemática do gênero relatório de estágio supervisionado, conforme fora observada por Silva e Fajardo-Turbin (2012, p. 20), ao reunir relatórios de estágio supervisionado produzidos em licenciaturas distintas, vinculadas a diferentes universidades brasileiras.

Tal instabilidade resultou na fragilidade do uso da categorização proposta por Ruqayia Hasan (1989) para caracterizar o que a autora denomina de estrutura potencial do gênero (EPG), composta por estágios ou elementos que integram a estrutura esquemática do gênero, desdobrando-se em elementos

12 "Genre theory suggests that texts which are doing different jobs in the culture will unfold in different ways, working through different stages or steps. This relationship between context and text is theorized as probabilistic, not deterministic".

13 "Genre represents the system of staged goal-oriented social processes through which social subjects in a given culture live their lives". 
obrigatórios, opcionais e recursivos (ou iterativos). ${ }^{14}$ Os textos apresentados pelos alunos-mestre, sob o rótulo de "relatório de estágio supervisionado", possuem configuração bastante diversa, marcada desde a extensão textual à organização textual em seçôes. É essa diversidade que nos faz lembrar dos portfólios.

No contexto da disciplina de estágio na licenciatura, um relatório pode se configurar em textos simples, com uma ou duas páginas, lembrando registros em notas de campo, ou em textos mais extensos, lembrando projetos de pesquisa ou de intervenção ou, ainda, artigos acadêmicos. A observação da diversidade de seçôes, conforme evidenciável nos quadros expositivos reproduzidos adiante - QUADRO 2 e QUADRO 3 -, motivou-nos a caracterizar uma estrutura esquemática do gênero mais pontual: elementos de contextualização imediata, introdução, desenvolvimento e consideraçōes finais ${ }^{15}$ (OLIVEIRA, 2012; OLIVEIRA; SILVA, 2011; SILVA, 2012a). Antes de revelar uma simplificação da estrutura esquemática, essa última mostra a funcionalidade restrita de aspectos estruturais como determinantes da caracterização do gênero focalizado. ${ }^{16}$

${ }^{14}$ Retomando os estudos de Ruqayia Hasan (1989), Désirée Motta-Roth e Viviane M. Heberle (2005, p. 18) esclarecem que "os elementos obrigatórios da EPG tendem a aparecer em uma ordem específica e sua ocorrência pode ser prevista por elementos contextuais. São componentes essenciais de qualquer texto completo de determinada configuração contextual e, portanto, são definidores do gênero. Elementos opcionais, por outro lado, pertencem àquela porção variável geralmente associada a dado gênero, mas que não precisa necessariamente estar presente em qualquer texto que tipicamente acompanha aquela atividade social específica. A ocorrência de elementos opcionais não é uma condição necessária, já que é prevista por um elemento contextual não definidor de gênero. Há ainda um terceiro elemento textual, denominado iterativo, que engloba aqueles elementos recursivos que aparecem mais de uma vez num evento comunicativo, sem seguir uma ordem rígida." (Grifo das autoras).

${ }^{15}$ Agradecemos aqui a Eliane de Jesus Oliveira (PIBIC/CNPq) pelo auxílio durante a escrita deste artigo.

${ }^{16}$ Optamos por não apresentar um quadro expositivo com a estrutura esquemática dos relatórios da licenciatura em Matemática pela enorme diversidade de seçôes com títulos diversos nos documentos investigados. 


\section{QUADRO 2}

Estrutura Esquemática - Licenciatura em Geografia

Capa $>$ Contracapa $>$ Dedicatória $>$ Agradecimentos $>$ Epígrafe $>$ Sumário $>$ Introdução $>$ Apresentação $>$ Pontos positivos $>$ Pontos negativos $>$ Justificativa $>$ Vivenciando a prática em sala de aula $>$ Objetivos $>$ Estágio efetivo $>$ Método de abordagem $>$ Desenvolvimento $>$ Descrição das aulas $>$ Prática em sala de aula $>$ Método (recursos $\mid$ procedimentos) $>$ Metodologia $>$ Relatório das aulas $>$ Relatório $>$ Referencial teórico $>$ Referencial teóricometodológico $>$ Base teórica $>$ Conclusão $>$ Considerações finais $>$ Anexos

\section{QUADRO 3}

Estrutura Esquemática - Licenciatura em História

Capa $>$ Contracapa $>$ Epígrafe $>$ Agradecimentos $>$ Índice $>$ Sumário $>$ Introdução $>$ Apresentação $>$ Aporte teórico $>$ Estágio supervisionado em História IV $>$ Relatório de estágio $>$ Relatório de estágio supervisionado em História $\mathrm{I}>$ Relatório $>$ Referencial teórico $>$

Desenvolvimento $>$ Relatório $>$ Conclusão $>$ Consideraçôes finais $>$ Anexos

Os elementos de contextualização imediata correspondem às seções que antecedem a introdução (capa, contracapa, epigrafe, agradecimentos, dedicatória, indice, sumário). A ocorrência desses elementos pré-textuais é bastante incerta, podendo envolver, inclusive, o uso de imagens. Os elementos introdução, desenvolvimento e considerações finais podem aparecer em seções marcadas textualmente por títulos diversos ou, até mesmo, integrar um texto corrido, apenas sendo depreendidos pela leitura atenta do relatório. Ao sinalizar o conteúdo tematizado nas seções, alguns títulos, por um lado, evidenciam o envolvimento do aluno-mestre na produção da escrita reflexiva, como pontos positivos, pontos negativos, vivenciando a prática em sala de aula. Há seções, por outro lado, cujos títulos nos remetem aos tradicionais gêneros acadêmicos, como justificativa, base teórica, referencial teórico e referencial teóricometodológico, evidenciando a tensão tematizada na segunda seção deste artigo.

Mas o que justificaria essa diversidade composicional do relatório de estágio supervisionado? As pesquisas científicas sobre a disciplina destacam a falta de consenso no tocante ao funcionamento mais produtivo do estágio supervisionado nas diferentes licenciaturas. No campo da LA, Luzia Bueno (2009, p. 46) destaca a falta de consenso dos formadores quanto às estratégias adotadas na disciplina para os alunos apresentarem as observações e reflexōes realizadas sobre as atividades práticas na escola de educação básica.

Tal incerteza recai sobre os usos do gênero relatório de estágio. Conforme mostram as pesquisas desenvolvidas por Fiad e Silva (2009, p. 126) e Wagner R. Silva e Aliny S. Mendes (2012), geralmente, não há nas disciplinas de estágio um 
momento em que seja realizado um trabalho mais sistematizado e formal sobre a escrita dos relatórios, mesmo nas licenciaturas em Letras, campo de investigação das pesquisas citadas. Em resposta a algum questionamento do aluno-mestre ou para acentuar algum aspecto do gênero, há formadores que apresentam orientação oral ou escrita, sendo essa última normalmente apresentada por meio de roteiro.

Além do formador da disciplina, do curso de licenciatura e da instituição de ensino superior, a própria proposta pedagógica da disciplina pode motivar alguma especificidade na composição do relatório. Em trabalho anterior, por exemplo, observamos algumas especificidades na estrutura esquemática dos relatórios, produzidos no primeiro estágio da licenciatura em Letras, em função, principalmente, da prática do estágio se restringir à observação de aulas, em escolas da educação básica, ao passo que, em outros estágios, o aluno-mestre também ministra aulas. Outro fator motivador de especificidades na estrutura composicional do gênero corresponde ao momento histórico da oferta do estágio, conforme destacado em Silva (2012a). Os dados investigados no referido trabalho correspondem a textos produzidos no período em que os estágios supervisionados ainda estavam sob a responsabilidade de formadores substitutos na instituição, sem titulação específica para atuação na área. Tais formadores eram vinculados ao governo estadual, sendo cedidos à universidade nos primeiros anos de federalização da então instituição pública estadual de ensino superior.

Nos referidos relatórios aparecem as seguintes especificidades na estrutura esquemática do gênero: caracterizaçâo socioeconômica; estrutura física e material; pessoal; estrutura; organização e funcionamento; planejamento escolar; direção e gestão da escola; avaliação. Esses títulos atribuídos às seções evidenciam um relatório marcadamente descritivo, o que pode ser confirmado com a análise previamente realizada dos dados, que mostrou um texto mais próximo da escrita impressionista informada previamente (SILVA, 2012a; SILVA; MELO, 2008).

\section{Discursos sobre o estágio supervisionado}

Analisamos aqui três passagens textuais representativas dos relatórios de estágio supervisionado, as quais ilustram discursos característicos dos elementos introdução, desenvolvimento e consideraçôes finais. ${ }^{17}$ Selecionamos

${ }^{17}$ Os exemplos aqui analisados foram selecionados a partir do trabalho de Tavares (2011), desenvolvido sob nossa orientação. Somos gratos a Elcia Tavares pelo auxílio em alguns momentos da escrita deste artigo. 
uma passagem das licenciaturas em História, Geografia e Matemática, respectivamente. Nas passagens textuais reproduzidas como exemplares dos dados analisados, focalizamos algumas escolhas lexicogramaticais na materialidade textual, as quais se destacam na leitura dos dados. Essas escolhas são analisadas à luz das metafunções da linguagem, propostas na LSF e tematizadas na terceira seção deste artigo, não significando que faremos uma análise classificatória. Porém, utilizamos das categorias como processo verbal, participante, circunstância, tema e articuladores. Trata-se de uma análise discursiva, na perspectiva proposta na LSF.

Optamos por analisar os momentos do relatório em que o alunomestre produz um texto mais próximo do que compreendemos por escrita reflexiva. Apesar de o aluno-mestre se mostrar alinhado ao paradigma de inovação das disciplinas escolares, as atividades didáticas propostas nas aulas ministradas nos estágios revelam dificuldade da didatização dos conteúdos de estudo específicos das disciplinas. Esses conteúdos não serão objeto de investigação deste artigo, uma vez que já foram focalizados por Elcia Tavares (2011) e Elcia Tavares e Wagner R. Silva (2012). Por inovação, compreendemos "deslocamento ou reconfiguração dos modos rotineiros de raciocinar/agir/avaliar", nas diferentes disciplinas escolares, "configuração essa impulsionada por demandas institucionais” (SIGNORINI, 2007, p. 9). Ou seja, inovar não significa necessariamente construir o inesperado, mas possibilitar ou trabalhar em função de algum tipo de deslocamento produtivo na ordem vigente.

É recorrente o uso da introdução do relatório pelo aluno-mestre para informar a proposta do estágio supervisionado. Usualmente, a disciplina é vista apenas como o momento de articulação entre teoria acadêmica e prática pedagógica, o que não parece ser vivenciado nas demais disciplinas curriculares das licenciaturas (SILVA, 2012b).

Diferentemente dessa tendência, na passagem da introdução do relatório, reproduzida no exemplo 1, adiante, o aluno-mestre constrói um posicionamento alinhado ao novo paradigma do ensino de História (dinâmica; interessante; de fácil aprendizagem), contrapondo-se a práticas pedagógicas caracterizadas pelo tradicionalismo e por práticas escolares decorativas. 


\section{Exemplo 1 - Introdução ${ }^{18}$}

Diante desse novo desafio é obvio que aconteça os deslizes, os tropeços pelo fato de não estarmos habituados, mais no decorrer do percurso vamos ganhando confiança e ampliando nossos conhecimentos pedagógicos. Trabalhamos considerando que $\mathrm{o}$ ensino de História precisa de uma reforma pedagógica dinamizando entre educando e educador com o objetivo de substituir as práticas pedagógicas decorativas até então implantadas nas escolas que de certa forma cumprem ordens de interesses particulares, portanto nós acadêmicos temos a responsabilidade de aplicar as teorias e as nova mentalidade na qual adquirimos na universidade com a finalidade de melhorar o ensino de História de forma dinâmica, objetiva, fugindo do tradicionalismo para que a mesma torne interessante e de fácil aprendizado. (Relatório de Estágio III - História, 2005).

No exemplo 1, o aluno-mestre caracteriza o estágio como "novo desafio", expressão nominal marcada por gradação positiva, a disciplina não seria, portanto, um desafio comum. O aluno-mestre parece dialogar diretamente com o formador, procurando eliminar alguma avaliação negativa das atividades relatadas da prática do estágio. Os denominados "deslizes" ou "tropeços" são caracterizados como "óbvios", procura-se evitar que o formador seja surpreendido por açōes transcorridas nas atividades práticas do estágio. $\mathrm{O}$ processo material semiotizado em "vamos ganhando" e "ampliando", seguidos respectivamente dos participantes "confiança" e "nosso conhecimento", fortalece a tentativa de eliminação da avaliação negativa.

O processo material, semiotizado pelas formas verbais "trabalhamos", "substituir", "aplicar", "adquirimos", "melhorar", "fugindo" e "torne" contribui para construir uma representação de aluno-mestre ativo, em consonância com as atuais orientações oficiais para o ensino de História, as quais propõem que o aluno participe do processo de construção do conhecimento histórico. Essa participação se daria pelo acesso do aluno da educação básica a textos diversos, com diferentes versões dos fatos históricos, possibilitando que o aluno realize leituras críticas comparativas entre diferentes textos (TAVARES, 2011). O paradigma da inovação também é fortalecido pela literatura científica produzida na área de ensino de História, conforme esclarece Maria Lima ao afirmar, por exemplo, que

18 Todas as passagens textuais foram reproduzidas conforme o original. Não realizamos adequações linguísticas, pois acreditamos a escrita original seja relevante para a pesquisa. 
nas aulas de história, as atividades que envolvem a produção escrita do estudante, na grande maioria das vezes, são extremamente escolarizadas e descontextualizadas, tendo como único destinatário o professor, que lê para corrigir, e não, para entrar em contato com $o$ que o estudante pensa ou com como ela expressa linguisticamente o que pensa. (LIMA, 2009, p. 236, grifos da autora).

No desenvolvimento, são narradas e apreciadas experiências vivenciadas pelo aluno-mestre durante a prática do estágio supervisionado. No exemplo 2 , adiante, reproduzimos uma passagem textual representativa desse fato, pertencente a um relatório da licenciatura em Geografia. Nessa passagem, também é discursivizada a necessidade de inovação na prática de ensino na escola de educação básica.

\section{Exemplo 2 - Desenvolvimento}

Em nossas aulas explicamos além de outros assuntos a Hidrografia Brasileira, tentamos através de aulas expositivas, exemplos usados no quadro e vídeos explicar a importância e utilização de forma renovável da Hidrografia Brasileira, porém todos os esforços não tiveram muito êxito, pois observamos que por causa desta estrutura montada pelos nossos governantes a grande maioria dos alunos que fazem parte do ensino médio e fundamental não estão preocupados com a aprendizagem e sim em se divertirem, da parte dos professores resta apenas fingirem que estáo dando aulas. (Relatório de Estágio VI - Geografia, 2008).

No exemplo 2, o processo material, semiotizado pela forma verbal "tentamos", seguido pela construção de circunstância "através de aulas expositivas, exemplos usados no quadro e vídeos", contribui para construir uma representação de aluno-mestre comprometido com a aprendizagem do aluno da escola básica, mas não responsável pelo fracasso da prática pedagógica. $\mathrm{O}$ processo mental ("observamos") evidencia uma situação improdutiva, no campo de estágio, descrita pelo aluno-mestre como estabilizada ("não estão"). Esse estado de coisa também é construído pelos processos materiais realizados por outros participantes integrantes do espaço complexo da sala de aula, como alunos que desejam se "divertirem" e professores que "apenas fingem".

Ainda que o aluno-mestre não assuma a responsabilidade pelo resultado pouco significativo das aulas ministradas, percebemos a dificuldade de didatização do conteúdo disciplinar a ser trabalhado em sala de aula. Assim como é comum em diversos relatórios de estágio supervisionado, parece mais tranquilo para o aluno-mestre analisar criticamente a ação realizada por outros atores e não necessariamente o próprio desempenho nas atividades práticas do 
estágio. Assim como é comum em outras licenciaturas, Flaviana G. Nunes e Sedeval Nardoque (2010), ao investigarem a prática de ensino de Geografia, afirmam que o aluno-mestre percebe

claramente que o aprendizado de conceitos, de temas e de conteúdos da geografia acadêmica recebidos na graduação tem conotação teórica e certo distanciamento daquela geografia ensinada na escola. Muitas vezes, os estagiários, durante a regência, têm grande dificuldade na transposição didática do conhecimento científico para os alunos, por não vivenciaram a aproximação teórico-prática esperada na formação acadêmica. (NUNES; NARDOQUE, 2010, p. 83).

O exemplo 3, adiante, revela a preocupação do aluno-mestre com a inovação do ensino de Matemática na educação básica. Além da constatação de algumas demandas no contexto do estágio na escola básica, são apresentados alguns encaminhamentos em resposta às demandas.

Exemplo 3 - Conclusão

Outro ponto importante que no aproveitamento que os alunos tem perante os conteúdos ministrados é a atenção, um dos fatores que tentei conseguir, porém, observei a principal causa pela falta de atenção é a dificuldade que os mesmos tem diante da disciplina matemática. Assim uma possível solução para a falta de estímulo em sala de aula é tornar a matemática uma disciplina com aplicações ao cotidiano e que a mesma não seja trabalhada apenas pelo professor de matemática, mas pelos professores das outras matérias, dessa maneira todos iriam ministrar aula de maneira interdisciplinares, aplicadas a realidade dos alunos e muito mais atrativas. (Relatório de Estágio III - Matemática, 2006).

No exemplo 3, observamos um parágrafo marcadamente argumentativo, o que é sinalizado já no início na passagem textual reproduzida por meio da expressão nominal "outro ponto importante", na posição temática da oração. $\mathrm{O}$ processo material "tentei conseguir" e o processo mental "observei” contribuem para a construção de um relatório como espaço discursivo da recontextualização de atividades realizadas por meio da reflexão sobre ação. Alguns articuladores textuais como "porém", "assim", "mas" e "dessa maneira", contribuem para a construção do posicionamento crítico do aluno-mestre nas conclusôes do relatório apresentado, além das formas adverbiais "apenas" e "muito mais atrativas".

A expressão nominal "uma possível solução", na posição temática, introduz uma abordagem interdisciplinar como alternativa para o problema observado pelo aluno-mestre no campo de estágio. O adjetivo "possível" parece contribuir para a 
construção da representação de aluno-mestre consciente do desafio do trabalho docente: a inovação da prática pedagógica não está condicionada ao desejo e à ação de um único integrante do espaço complexo da sala de aula. Na educação básica, o próprio aluno, acostumado às práticas da tradição escolar, pode resistir à inovação, conforme mostra Geovana F. Melo ao relatar a experiência vivenciada por estagiários em aulas de Matemática na EJA. Na experiência relatada, os alunos resistiram às atividades diferenciadas propostas pelos alunos-mestre, uma vez que aprender, para os alunos da EJA, "estava ligado à quantidade de exercícios que a professora passava no quadro" (MELO, 2008, p. 108).

O enfoque sobre os relatórios escritos inevitavelmente nos informa sobre as práticas de escrita acadêmica nas licenciaturas focalizadas. Revela-nos algumas fragilidades do trabalho com a escrita na formação inicial do professor nesses cursos. Essa fragilidade pode resultar na criação de muitas demandas futuras para o fortalecimento do letramento do professor em função das práticas de escrita características do local de trabalho. Bem sabemos que a escola de educação básica, principal agência de letramento em nossa sociedade, requer desenvoltura do professor para atuar em sintonia com as práticas de escrita organizadoras do trabalho docente. Enquanto formadores, precisamos nos questionar se nossa prática profissional, em quaisquer que sejam as licenciaturas, também está em sintonia com tais exigências pontuadas e muitas outras não tematizadas aqui.

Parece-nos que, inevitavelmente, sobre os estágios supervisionados das licenciaturas recai mais fortemente a responsabilidade de formação dos agentes de letramento, compreendidos, de acordo com Angela B. Kleiman (2006, p. 86), como "atores sociais" que mobilizam "as capacidades dos membros do grupo", favorecem "a participação de todos segundo suas capacidades", criam "as condições necessárias para a emergência de diversos atores, com diversos papéis, segundo as necessidades e potencialidades do grupo".

Os formadores não devem se eximir de exercer a função de agentes de letramento, o que também abrange o uso produtivo dos relatórios de estágio supervisionado. Ou seja, o aluno-mestre precisa ser preparado "para analisar criticamente", por meio do exercício da escrita reflexiva, de forma menos impressionista, "as experiências do estágio supervisionado à luz das teorias acadêmicas de referência, contribuindo para o aprimoramento da própria prática profissional". Afirmamos ainda que "a atividade de escrita dos relatórios de estágio supervisionado pode contribuir para modelar o fazer pedagógico característico dos agentes de letramento" (SILVA, 2012b, p. 41). 


\section{Considerações finais}

Ao finalizar a exposição da pesquisa científica focalizada, destacamos três questôes teórico-práticas que se sobressaíram no percurso investigativo realizado neste artigo:

1. o trabalho com a linguagem em contexto de formação das licenciaturas diversas precisa ser considerado de forma mais significativa nas investigações realizadas no âmbito da LA. Configura-se como uma questão de interesse para o campo dos estudos do letramento do professor em formação inicial;

2. os aspectos formais e funcionais precisam ser complexificados nos estudos descritivos de gêneros textuais, principalmente quando o interesse investigativo recai sobre questōes aplicadas envolvendo a linguagem, como os usos da escrita na formação inicial de professores. Os relatórios de estágio supervisionado correspondem aos textos identificados como tais pelos próprios usuários no contexto de circulação do gênero;

3. o diálogo entre diferentes disciplinas se faz necessário na abordagem dos gêneros textuais proposta na LSF, em especial quando se trabalha com a noção de contexto de cultura, onde inúmeras práticas sociais moldam os gêneros, compreendidos como formas linguístico-discursivas de ação pela linguagem nas diversas esperas enunciativas. Nesta investigação, algumas pesquisas científicas sobre estágios supervisionados em diferentes licenciaturas, com enfoque fortemente pedagógico, foram essenciais na reconstituição do contexto de cultura dos documentos investigados.

As abordagens interdisciplinares ou, até mesmo, transdisciplinares contribuem para visibilizar práticas sociais configuradoras do contexto de cultura, possibilitando que a investigação ultrapasse o plano dos mecanismos linguísticos propriamente ditos. A abordagem teórica da LSF pode ser ampliada quando desenvolvida dentro da perspectiva transdisciplinar da LA, o que ainda merece ser mais bem aprofundado em pesquisas científicas futuras.

Finalmente, destacamos a importância do trabalho mais sistematizado com a escrita acadêmica, no contexto de formação inicial de professores, nos estágios supervisionados obrigatórios, nas diferentes licenciaturas, em especial nos cursos em que a linguagem não é o principal objeto de estudo. Para o formador, o trabalho com o gênero relatório de estágio supervisionado não poderia ser uma escolha aleatória para a disciplina, apenas motivada pela tradição das práticas vigentes nas licenciaturas, mas justificada por razões pedagógicas conscientes por parte do formador. 


\section{Referências}

BARBARA, L.; MACÊDO, C. M. de M. Linguística sistêmico-funcional para análise de discurso: um panorama introdutório. Cadernos de Linguagem e Sociedade, Brasília, v. 10, n. 1, p. 89-107, 2009.

BARTON, D.; PAPEN, U. What is the Anthropology of Writing? In:

(Org.). The Anthropology of Writing: Understanding Textually-Mediated Worlds. London: Continuum, 2010. p. 3-32.

BUENO, L. A construção de representações sobre o trabalho docente: o papel do estágio. São Paulo: Educ; Fapesp, 2009.

BURTON, J. Reflective Writing - Getting to the Heart of Teaching and Learning. In:__ et al. (Ed.). Reflective Writing: a Way to Lifelong Teacher Learning. Berkeley: TESL-EJ, 2009. p. 1-11. Disponível em: <http://tesl-ej.org/books/ reflective_writing.pdf>. Acesso em: 6 set. 2012.

CELANI, M. A. A. A relevância da Linguística Aplicada na formação de uma política educacional brasileira. In: FORTKAMP, M. B. M.; TOMITCH, L. M. B. (Org.). Aspectos da Linguística Aplicada: estudos em homenagem ao professor Hilário Inácio Bohn. 2. ed. Florianópolis: Insular, 2008. p. 17-32.

EGGINS, S. An Introduction to Systemic Functional Linguistics. London: Continuum, 2004.

EGGINS, S.; MARTIN, J. R. Genres and Registers of Discourse. In: DIJK, T. A. van (Ed.). Discourse as Structure and Process. London: SAGE, 1997. p. 230-256.

FIAD, R. S.; SILVA, L. L. M. da. Escrita na formação docente: relatos de estágio. Acta Scientiarum: Language and Culture, Maringá, v. 31, n. 2, p. 123-131, 2009.

GISI, M. L.; MARTINS, P. L. O.; ROMANOWSKI, J. P. O estágio nos cursos de licenciatura. In: Romilda T. Ens; Dilmeire S. A. R. Vosgerau; Marilda A. Behrens (Org.). Trabalho do professor e saberes docentes. Curitiba: Editora Champagnat, 2009. p. 201-215.

HALLIDAY, M. A. K. Explorations in the Functions of Language. London: Edward Arnold, 1973.

KLEIMAN, A. B. Formação do professor: retrospectivas e perspectivas na pesquisa. In: . (Org.). A formação do professor: perspectivas da Linguística Aplicada. Campinas: Mercado de Letras, 2001. p. 13-35.

. O estatuto disciplinar da Linguística Aplicada: o traçado de um percurso, um rumo para o debate. In: SIGNORINI, I.; CAVALCANTI, M. C. (Org.). Linguistica Aplicada e transdisciplinaridade. Campinas: Mercado de Letras, 1998. p. 51-77. 
KLEIMAN, A. B. Processos identitários na formação profissional: o professor como agente de letramento. In: CORRÊA, M. L. G.; BOCH, F. (Org.). Ensino de língua: representação e letramento. Campinas: Mercado de Letras, 2006. p. 75-91.

LIMA, M. Ensinar a escrever no âmbito do livro didático de história. In: ROCHA, H. A. B.; REZNIK, L.; MAGALHÃES, M. de S. (Org.). A história na escola: autores, livros e leituras. Rio de Janeiro: FGV, 2009. p. 227-242.

MARTIN, J. R. Analysing Genre: Functional Parameters. In: CHRISTIE, F.; MARTIN, J. R. (Ed.). Genre and Institutions: Social Processes in the Workplace and School. London: Cassell, 1997. p. 3-39.

MARTIN, J. R.; WHITE, P. R. R. The Language of Evaluation: Appraisal in English. New York: Palgrave Macmillan, 2005.

MELO, G. F. Estágio na formação inicial de professores: aguçando o olhar, desenvolvendo a escuta sensível. In: SILVA, L. C. da; MIRANDA, M. I. (Org.). Estágio supervisionado e prática de ensino: desafios e possibilidades. Araraquara: Junqueira \& Marin, 2008. p. 85-113.

MELO, L. C. de. Relatórios de estágio supervisionado em ensino de língua inglesa: práticas auto-reflexivas de escrita. 2011. 148 f. Dissertação (Mestrado em Ensino de Língua e Literatura) - Universidade Federal do Tocantins, Araguaína, 2011. MIRANDA, M. I. Ensino e pesquisa: o estágio como espaço de articulação. In: SILVA, L. C. da; MIRANDA, M. I. (Org.). Estágio supervisionado e prática de ensino: desafios e possibilidades. Araraquara: Junqueira \& Marin, 2008. p. 15-36. MOTTA-ROTH, D.; HEBERLE, V. M. O conceito de "estrutura potencial do gênero" de Ruqayia Hasan. In: MEURER, J. L.; BONINI, A.; MOTTA-ROTH, D. (Org.). Gêneros: teorias, métodos, debates. São Paulo: Parábola, 2005. p. 12-28. NUNES, F. G.; NARDOQUE, S. O estágio supervisionado na formação do professor em Geografia. In: GONÇALVES, A. V.; PINHEIRO, A. S.; FERRO, M. E. (Org.). Estágio supervisionado e práticas educativas: diálogos interdisciplinares. Dourados: Editora UEMS, 2011. p. 249-267.

OLIVEIRA, E. J. Caracterização do gênero relatório de estágio supervisionado em três licenciaturas. Tocantins, 2012. Artigo. Não publicado.

OLIVEIRA, E. J.; SILVA, W. R. Caracterização do relatório de estágio supervisionado na licenciatura em Geografia. In: SILVA, N. L. da; ALMEIDA, V. de (Org.). Reflexões sobre ensino e formação de professores: diálogos entre educação superior e básica. Palmas: Nagô; CAPES, 2011. p. 115-125.

PENNYCOOK, A. Linguística Aplicada pós-ocidental. In: CORACINI, M. J.; BERTOLDO, E. S. (Org.). O desejo da teoria e a contingência da prática: discursos sobre e na sala de aula (língua materna e língua estrangeira). Campinas: Mercado de Letras, 2003. p. 21-59. 
PENNYCOOK, A. A Linguística Aplicada dos anos 90: em defesa de uma abordagem crítica. In: SIGNORINI, I.; CAVALCANTI, M. C. (Org.). Linguistica Aplicada e transdisciplinaridade. Campinas: Mercado de Letras, 1998. p. 23-49. SIGNORINI, I. Significados da inovação no ensino de Lingua Portuguesa e na formação de professores. Campinas: Mercado de Letras, 2007.

. Do residual ao múltiplo e ao complexo: o objeto da pesquisa em Linguística Aplicada. In: SIGNORINI, I.; CAVALCANTI, M. C. (Org.). Linguística Aplicada e transdisciplinaridade. Campinas: Mercado de Letras, 1998. p. 99-110.

. Gêneros catalisadores, letramento \& formação do professor. São Paulo: Parábola, 2006.

SILVA, W. R. Análise crítica de relatórios de estágio supervisionado: contribuiçōes para a formação inicial do professor. Tocantins, 2012a. Artigo. Não publicado.

. Práticas de escrita na formação inicial do professor nas licenciaturas. In: SILVA, W. R. (Org.). Letramento do professor em formação inicial: interdisciplinaridade no estágio supervisionado da licenciatura. Campinas: Pontes, 2012b. p. 29-51. SILVA, W. R.; FAJARDO-TURBIN, A. E. Como fazer relatório de estágio supervisionado: formação de professores nas licenciaturas. Brasília: Liber Livro, 2012.

. Relatório de estágio supervisionado como registro da reflexão pela escrita na profissionalização do professor. Revista Polifonia, Cuiabá, v. 18, n. 23, p. 97-123, 2011. Disponível em: <http://periodicoscientificos.ufmt.br/ojs/ index.php/polifonia/article/download/25/264>. Acesso em: 6 set. 2012.

SILVA, W. R.; MELO, L. C. de. Relatórios de estágio supervisionado como gênero discursivo mediador da formação do professor de língua materna. Trabalhos em Linguistica Aplicada, Campinas, v. 47, n. 1, p. 131-149, 2008.

SILVA, W. R.; MENDES, A. S. Prática de reescrita na formação inicial de professores: um estudo da produção do gênero relatório de estágio supervisionado. Caderno de Letras, Pelotas, v. 18, n. 1, 2012. No prelo.

TAVARES, E. Práticas de escrita escolar propostas na formação inicial de professores de diferentes licenciaturas: investigando relatórios de estágio e diretrizes curriculares oficiais. 2011. 186 f. Dissertação (Mestrado em Ensino de Língua e Literatura) - Universidade Federal do Tocantins, Araguaína, 2011.

TAVARES, E.; SILVA, W. R. Práticas de escrita escolar nos estágios supervisionados das licenciaturas em Geografia, História e Matemática. In: SILVA, W. R. (Org.). Letramento do professor em formação inicial: interdisciplinaridade no estágio supervisionado da licenciatura. 1. ed. Campinas: Pontes, 2012. p. 231-255.

VAN LEEUWEN, T. Discourse and Practice: News Tools for Critical Discourse Analysis. Oxford: Oxford University Press, 2008. 
VIAN JR., O. O artigo na família de gêneros acadêmicos: notas sobre aspectos tipológicos, topológicos e seu papel no ensino-aprendizagem de língua. In: BARBARA, L.; MOYANO, E. (Org.). Textos e linguagem acadêmica: exploraçóes sistêmico-funcionais em espanhol e português. Campinas: Mercado de Letras, 2011. p. 67-86.

VILLAS BOAS, B. M. de F. Portfólio, avaliação e trabalho pedagógico. 7. ed. Campinas: Papirus, 2010.

Recebido em 11/07/2012. Aprovado em 28/08/2012. 